\title{
O JOGO E A EDUCAÇÃO GREGA: PAIDIA ENQUANTO ELEMENTO FORMATIVO DA PAIDEIA
}

\author{
The Game and the Greek Education: \\ Paidia as Formative of Paideia
}

\author{
Marcelo Prado Amaral Rosa \\ Michel Mendes \\ Roniere dos Santos Fenner \\ (UFRGS, Brasil)
}

\begin{abstract}
Resumo
Os jogos e a educação eram conquistas pelas quais os gregos apresentam estima. Dentre os jogos, destacam-se os de caráter competitivo, conhecidos como âgon - por possuírem regras, e de diversão, conhecidos por Paidia - jogos sem regras, destinados às crianças. Já na educação, Paideia, inicialmente buscavam a formação ideal para as crianças, o que posteriormente passa a ser concebido como uma formação completa, a formação do homem. Dessa forma, o objetivo do trabalho é identificar as relações existentes entre o jogo (Paidia) e a educação (Paideia), com a finalidade de explorar as proximidades entre tais esferas na educação, destacando a relevância do termo Paidia enquanto elemento formativo da Paideia grega. O trabalho possui abordagem teórica e salienta evidências que apontam a relevância do termo Paidia para a educação grega. Sublinha-se a existência da relação de consequência entre a Paidia e Paideia, uma vez que a primeira se comporta como instrumento prévio de ensino sobre questões políticas e éticas do futuro cidadão.
\end{abstract}

Palavras-chave: Paidia | Paideia | Educação.

\begin{abstract}
Games and education achievements by which the Greeks have estimated. Among the games, the stand out of competitive character, known as âgon - by having rules, and fun, known for Paidia - Games without rules, aimed at children. In the education, Paideia, initially sought the ideal training for children, which later becomes conceived as a complete formation, the formation of man. Thus, the objective is to identify the relationship between the game (Paidia) and education (Paideia), in order to explore the vicinity of such spheres in education, highlighting the relevance of Paidia term as formative of the Greek Paideia. The work has theoretical approach and emphasizes evidence indicating the importance of Paidia term for the Greek education. It stresses the existence of consequence relationship between Paidia and Paideia, since the first behaves like previous instrument of education on political and ethical issues of the future citizen.
\end{abstract}

Keywords: Paidia | Paideia | Education. 


\section{Considerações iniciais}

Os Gregos foram responsáveis por grandes acontecimentos históricos, como a construção da Mitologia, Filosofia, História, Democracia, Poesia, Música, Arquitetura, do Teatro, de Colégios, dos Jogos Olímpicos e outros (CAMBI, 1999; JAEGER, 1995, MANACORDA, 1992). Dentre suas grandes construções, destaca-se o termo Paideia.

Paideia apresenta duas concepções: i) uma ligada ao período Arcaico (800 - 500 a. C.); e ii) a outra ao período Clássico (500 - 338 a. C.). A concepção do primeiro está ligada à ideia de formação da criança grega, de uma educação e cultura voltada para seu desenvolvimento, enquanto a segunda é voltada para a formação do homem, não mais apenas da criança, e sim do desenvolvimento do individuo de maneira integral.

As alterações na concepção desse termo foram vitais para o entendimento da educação grega. A transformação significou um avanço para os ideais gregos de educação, passando de apenas uma criação de crianças, para uma formação completa de adultos (JAEGER, 1995; BRAGA, 2000).

Na educação grega, os jogos com finalidades educacionais estavam à margem daqueles voltados ao desenvolvimento do corpo. Esses eram apenas de valor físico, voltados ao culto do corpo e das práticas olímpicas. No entanto, neste artigo, busca-se discutir o termo Paideia e sua relação com os jogos voltados à educação.

Dessa forma, o objetivo do trabalho é identificar as relações existentes entre o jogo (Paidia) e a educação (Paideia), com a finalidade de explorar as proximidades entre tais esferas na educação, destacando a relevância do termo Paidia enquanto elemento formativo da Paideia grega. $\mathrm{O}$ trabalho possui abordagem teórica, buscando salientar a relevância do termo Paidia para a educação grega.

\section{Da Paidia para a Paideia: a infância e os jogos para os gregos}

Os jogos sempre foram atividades pelas quais os gregos apresentavam estima. Fato esse que originou a criação dos Jogos Olímpicos em 776 a.C., os quais, segundo Cambi (1999), eram jogos em homenagem a Zeus, o principal Deus da cultura grega. Ainda, de acordo com Cambi (1999), os jogos olímpicos eram capazes de ensinar, pois demandavam raciocínio, inteligência, comunicação e imaginação nos desafios que surgiam durante os jogos. Os jogos, por demandarem preparo, exigiam dedicação e cultivo do corpo, o que só era alcançado pela prática de jogos, ginástica e combates corporais que, ao serem realizados, favoreciam o desenvolvimento da inteligência, da astúcia e da força, fundamentais para as competições (CAMBI, 1999).

No entanto, os jogos olímpicos eram eventos, apenas, para os homens, em sua maioria aristocrata, pois dispunham do ócio para aperfeiçoar e treinar o corpo para as competições. Já os escravos, as mulheres e crianças não podiam competir (CAMBI, 1999).

Para os gregos, segundo Cambi (1999), a infância não apresentava um período do desenvolvimento humano em que eram necessários cuidados específicos, e sim um momento de provações, de enfrentar e resistir às dificuldades que se colocassem, tanto que o pai, muitas vezes, decidia o futuro da criança: se ela seria ou não abandonada. Quando criadas, as crianças sofriam graves situações de abandono, estando privadas de afetividade e cuidados básicos em relação à sua saúde, ou seja, a mercê da não concepção grega de infância para o período.

A infância cresce em casa, controlada pelo "medo do pai", atemorizada por figuras míticas [...] gratificada com brinquedos [...] e entretida pelos jogos, mas sempre colocada a margem da vida social. Ou então por esta brutalmente corrompida, submetida à violência, a estupro, a trabalho, e até a sacrifícios rituais (CAMBI, 1999, p. 82). 
Para Platão (427 a.C - 348 a.C), conforme destaca Jaeger (1995), a educação das crianças nos anos iniciais deveria ser incentivada ao ato de mover-se, colocar o corpo em movimento, através de balanços, danças, cantos, caminhadas e outros. Todas essas atividades visavam conhecer o "mundo" e obter novas experiências, buscando desenvolver nas crianças sensações agradáveis e desagradáveis, tornando-as menos sensíveis. Segundo Kohn (2013), "essa primeira educação da alma deve ser lúdica, espalhada entre os jogos e não forçada, já que nenhum saber permanece nela por força.” (p. 22).

Cabe destacar que para Platão, as crianças mais novas naturalmente despertavam seus instintos de invenção e criação de jogos, sempre que estivessem juntas (meninos e meninas). Ou seja, alguns jogos "nascem" do instinto natural da criança, anteriormente a educação. "Nesta idade, são as crianças, quando se juntam, que devem inventar os seus jogos, sem que estes lhes sejam prescritos." (JAEGER, 1995, p. 1353).

A atenção da cultura grega voltava-se para à educação e construção da polis, no qual, existia uma relação entre a educação, a pólis e as crianças. No entanto, o cuidado das crianças deveria ser direcionado para a vida adulta da polis, buscando ensiná-las comportamentos adequados para uma vida em sociedade. Dessa forma, necessitava-se pensar a forma de cuidado destinado às crianças, planejando uma educação com intencionalidades políticas, pois "há uma conexão direta entre as qualidades de uma pólis e as dos indivíduos que a compõem.” (KOHN, 2003, p. 13).

Platão associava a infância como uma primeira etapa da vida humana, e projetava, na mesma, as consequências que surgiriam na vida adulta, pois acreditava que as aprendizagens da infância seguiriam para toda a vida, tendo importância na criação dos sujeitos. A educação para Platão era importante durante toda a vida do ser humano, mas em alguns momentos, como na infância faziase ainda mais necessária (KOHN, 2013).

A criança era percebida como o princípio, as ações estavam voltadas para formar a pessoa futura, a questão não era formar as crianças, mas planejar a pólis adequada. Segundo Kohan (2003), podem-se identificar traços que marcaram o pensamento de Platão em relação à infância, ao conceber o período:

a) como possibilidade (as crianças podem ser qualquer coisa no futuro); b) como inferioridade (as crianças - como as mulheres, estrangeiros e escravos - são inferiores em relação ao homem adulto cidadão); c) como superfluidade (a infância não é necessária à pólis); d) como material da política (a utopia se constrói a partir da educação das crianças) (p. 11, grifo nosso).

Para Platão era importante criar ocupações para as crianças como jogos que ensinassem a alguma coisa, em especial a aritmética, livrando-se assim da ignorância que torna o homem adulto, vergonhoso e ridículo (MANACORDA, 1992).

Para Platão, segundo Manacorda (1992), os gregos deveriam aprender tanto quanto os egípcios as noções de aritmética e geometria, e para isso, ainda, no período demótico (1069 - 333 a. C.), os Egípcios inventaram para as crianças estratégias para ensinar cálculos e aritmética, por meio de jogos e objetos, como:

"[...] subdivisão de maçãs e de coroas entre um número mais ou menos grande de alunos, dando a cada um sempre o mesmo número; ou distribuição alternada e sucessivamente, segundo a sua ordem habitual, [...] outros, após terem misturado em certo número de taças de ouro, de prata, de bronze e de outros metais, distribuem todas essas taças para o jogo de várias formas, adaptando ao jogo as aplicações úteis dos números necessários." (PLATÃO, VII, 819 b-d apud MANACORDA, 1992, p. 37).

Para Kohn (2013) "os jogos infantis serão regulamentados rigorosamente para que as crianças desenvolvam desde pequenas a estima e o apego pelas leis.” (p. 25). Especialmente em seu diálogo “As Leis", Platão (1999), discute as questões relacionadas à organização da sociedade e suas regras 
e a educação infantil e os jogos. Segundo o filósofo, a utilização dos jogos pelas crianças poderia determinar o futuro da sociedade, sob duas condições: a primeira tratava de realizar jogos sempre com as mesmas condições, proporcionando o entendimento de que as regras são inalteradas; a segunda tratava justamente do contrário, ao permitir jogos livres e com alterações de regras, acabariam influenciando e construindo prazeres e posturas sem limites.

Nesse sentido, no diálogo A república, Sócrates e Adimanto (irmão de Platão) discutem os aspectos da vida em sociedade, em que afirmam a necessidade de utilizar jogos que possuam regras, para ensinar as crianças às leis de maneira prazerosa e doce, não as deixando, assim, desregradas e livres na vida (PLATÃO, 1965, 2001). Caso contrário, segundo Platão (1965, 2001), o futuro da sociedade grega estaria condenado a homens não virtuosos, não cumpridores da lei e desonestos.

De acordo com Henriques (2005), a educação grega partia dos jogos, sendo entendida como uma atividade livre, natural e espontânea do ser humano e dos demais animais. Para Platão, segundo Jaeger (1995), a poesia e a música, juntamente com a gramática, a retórica e a dialética possuíam o poder de modelar a alma do homem. Porém, o processo de ensino dessas habilidades deveria ser sem violência, pois na alma nada caberia pela força. Isso refletia no processo educativo das crianças, conforme salienta Platão (2000): "[...] nunca ensines nada às crianças por meio violento, mas à guisa de brinquedo: é como melhor poderás observar as aptidões de cada um. [...] É o único método, [...] que fixa solidamente no espírito os conhecimentos." (Livro VII, 537a - 537b), além de ser pelo jogo única forma de se atingir o logos, isto é, o conhecimento.

O cuidado por uma educação estruturada é marcada nos diálogos de Platão, conforme descrito nos últimos parágrafos. Ele ainda destaca no Diálogo "As Leis", a importância do brincar para o desenvolvimento de habilidades e projeções futuras dos infantes. Para ele, é fundamental um aprender brincando, um aprender fazendo:

O que afirmo é que todo homem que pretende ser bom em qualquer atividade precisa dedicar-se à prática dessa atividade em especial desde a infância utilizando todos os recursos relacionados a sua atividade, seja em seu entretenimento, seja no trabalho. Por exemplo, o homem que pretende ser um bom construtor necessita (quando menino) entreter-se brincando de construir casas, bem como aquele que deseja ser agricultor deverá (enquanto menino) brincar de lavrar a terra. Caberá aos educadores dessas crianças supri-las [sic] com ferramentas de brinquedo moldadas segundo as reais. Além disso, dever-se-á [sic] ministrar a essas crianças instrução básica em todas as matérias necessárias; sendo, por exemplo, ensinado ao aprendiz de carpinteiro sob forma de brinquedo o manejo da régua e da trena, àquele que será um soldado como montar e demais coisas pertinentes. E assim, por meio de seus brinquedos e jogos, nos esforçaríamos por dirigir os gostos e desejos das crianças para a direção do objeto que constitui seu objetivo principal relativamente à idade adulta (PLATÃO, s/d, p. 91-92).

Durante o período dos três aos seis anos de idade, de acordo com Jaeger (1995), Platão indicava a necessidade de educar as crianças reunindo-as em templos em seus povoados, por meio de jogos lúdicos. Segundo ele, essa prática estaria atrelada à formação do caráter nas crianças. Essa nova posição de Platão perante aos jogos condenava, de certa forma, o uso da competição, uma vez que prejudicava o valor educativo do jogo e não colaborava para a construção do caráter e da personalidade do homem.

É certo que nos poucos séculos da história grega, em que a competição dominou a vida da sociedade, também presenciaram os grandes jogos sagrados que uniram toda a Hélade em Olímpia, no Istmo em Delfos e em Neméia. Mas nem por isso deixa de ser verdade que o espírito de competição dominou a cultura helênica tanto antes desses séculos como depois (HUIZINGA, 2000, p. 55).

A visão estruturante dos jogos, para Platão, era limitada ao período da infância, compreendido até os seis anos de idade. Até esse momento, de acordo com Jaeger (1995), as crianças possuíam liberdade e eram incentivadas a desenvolver capacidades inventivas. Posteriormente, 
predominavam jogos fixos e de espírito concreto, controlados pelo estado. Era também, nesse momento que havia a separação entre meninos e meninas.

[...] Platão inicia um novo esclarecimento de base sobre o valor educativo do jogo, o qual até então fora completamente ignorado por todas as cidades. [...]. O problema do jogo deve tê-lo preocupado na velhice com intensidade maior do que nunca, e certamente como meio para o desenvolvimento precoce de um ethos adequado (JAEGER, 1995, p. 1356).

Para os Gregos, conforme Jaeger (1995) e Campi (1999), o termo Paideia significa educação, cultura, a formação do menino-criança que posteriormente passou a englobar a formação do homem, que não se limita à infância, e sim prossegue por toda vida. Essa dupla concepção de Paideia construída pelos gregos inicialmente concebia a formação da educação para a criança (período arcaico), alternando-se para uma educação completa, da criança ao adulto, de corpo e espírito (período clássico).

Diferentemente de Paideia, o termo Paidia apresenta menor utilização, sendo pouco discutido. Segundo Jaeger (1995), o termo significava jogo, um "mero passatempo" (p. 920), já, para Caillois (1990), Paidia "tem por raiz o nome de criança" (p. 48), atrelada à "diversão, turbulência, improviso, [...] certa fantasia.” (p. 32). Paidia associa-se a atividades com liberdade, alegria, improvisação, um jogo espontâneo sem regras que geralmente não existe competição ou disputa. Baratieri (2014) complementa o entendimento de Paidia apresentando sua raiz etimológica "A raiz do vocábulo é pais, paidos, criança, menino, donde o verbo paidzo: brincar, divertir-se, ser jovial; dançar, [...] Pela relação com pais, Paidia também está relacionado a Paideia: cuidado com as crianças, formação, educação, cultura.” (p. 100).

Na Grécia, o jogo assume duas concepções segundo Caillois (1990): o âgon, que significa competição e disputa, regida por regras, e Paidia, que significa jogo infantil, movido pela diversão e livre de regras. Os gregos valorizavam dois tipos de jogos: os jogos de simulação, como os jogos de cena e de circo (considerados não sérios); e na utilização de jogos sérios, voltados ao rito religioso (como os Jogos Olímpicos). Para os gregos, as corridas a pé proporcionavam abalos na estrutura do solo, isso acarretaria em uma reanimação das energias dos vegetais, ou seja, os jogos atléticos ou olímpicos reanimavam a natureza (CAMBI, 1999).

Segundo Jeager (1995), Platão acreditava que as crianças poderiam aprender jogando, e dessa forma, o jogo faria parte da educação infantil e juvenil. Assim, o jogo seria anterior à cultura, Paidia sucederia Paideia:

Os jogos - Paidia - constituem a mola fundamental da educação - paidea - que, na Grécia, não se limita à infância, mas prossegue durante toda a vida. É nos jogos, concursos e festas que o indivíduo adquire a virtude e recebe a forma conveniente (FRONTISI-DUCROUX, 1988, p. 41 apud BROUGÈRE, 1998, p. 41).

Nesse sentido, outro autor corrobora com a discussão e aponta uma característica essencial do jogo:

O jogo é fato mais antigo que a cultura, pois esta, mesmo em suas definições menos rigorosas, pressupõe sempre a sociedade humana; mas, os animais não esperaram que os homens os iniciassem na atividade lúdica. É-nos possível afirmar com segurança que a civilização humana não acrescentou característica essencial alguma à idéia geral de jogo. Os animais brincam tal como os homens (HUIZINGA, 2000, p. 5).

Paidia, enquanto jogo, está submetida à Paideia, educação, pois assume a função de modelar a vida social e pessoal, uma vez que é considerado um método de aprendizagem dos saberes necessários à educação. Porém, ressalta-se o apresentado por Huizinga (2000), ao salientar que o jogo é anterior à cultura, sendo menos valorizada pelo valor que se atribuiu ao termo Paideia historicamente. 
Contrariando o pensamento platônico e evidenciando um rompimento entre o jogo e a finalidade educacional, Aristóteles (2006) defende o jogo por outro olhar.

Para ele, o jogo justificava-se pela e para reposição de energias, por meio do relaxamento e descanso, ele existe pelo trabalho e só para o trabalho. Aristóteles (385 a.C - 322 a.C) acreditava que o fim do ser humano devesse ser virtuoso, e a essa virtude atribua-se um sério esforço e não um simples jogo. A visão aristotélica criticava o uso do jogo em situações não resultantes de esforço ou trabalho.

\begin{abstract}
Se o repouso e o trabalho são ambos indispensáveis, o repouso é pelo menos preferível, e é uma questão importante saber em que se deve empregar o lazer. Certamente não no jogo; senão, o jogo seria o nosso fim último. Se possível, é melhor descartar o jogo entre as ocupações. Quem trabalha precisa de descanso: o jogo não foi imaginado senão para isto. $\mathrm{O}$ trabalho é acompanhado de fadiga e de esforços. É preciso entremeá-lo convenientemente de recreações, como um remédio. O descanso é ao mesmo tempo um movimento da alma e um repouso, pelo prazer de que se acompanha (ARISTÓTELES, 2006, p. 80).
\end{abstract}

A partir desse pensamento, o jogo passa a ser visto como algo não sério e a vida demandava situações opostas ao que o jogo proporcionava. O trabalho demandaria o lazer, algo que para Aristóteles é diferente do jogo.

A aproximação entre os grandes pensadores gregos, Platão e Aristóteles, possibilitou a identificação do jogo por dois caminhos: o jogo como meio de ensino, para Platão, e o jogo como meio para o relaxamento da alma. Tais concepções refletem o caminhar do pensamento filosófico e pedagógico no tempo, sendo reconstruído subjetivamente e seguindo o "pensar" dominante.

\title{
Considerações finais
}

A utilização e valorização do jogo pelos gregos esteve associada ao período histórico-cultural no qual a importância estava depositada nos jogos ginásticos e atléticos, uma vez que o corpo representava um ideal de beleza, ao mesmo tempo que preparava para o combate e para as guerras, que nesse período faziam-se constante.

O jogo sempre esteve presente na sociedade humana, não de maneira inata, e sim como uma construção sócio-cultural, e na Grécia não foi diferente. Pode-se considerar o jogo um dos instrumentos propulsores utilizados para estruturar o ideal de formação educacional grego, mesmo que pouco discutido na literatura disponível.

O jogo infantil tinha, para os gregos, a função de instruir, impor as regras e leis da pólis, por meio da diversão, sem competição. Paidia e Paideia se relacionam no sentido de um ser o instrumento necessário para a realização de determinado objetivo. Nesse caso, os jogos para as crianças seriam os primeiros degraus a serem alcançados durante a fase de maturação do pensamento referente às normas vigentes, estruturando os processos educativos que viriam posteriormente.

Além de ser um recurso destinado à diversão, o jogo possui finalidades educativas, seja ele individual ou grupal, pois coloca em movimento sentimentos, comportamentos, conhecimentos e habilidades. O jogo promove a interação sujeito- sujeito e sujeito-objeto, o que incentiva a comunicação entre os participantes, auxilia na aquisição de experiências e proporciona um desenvolvimento integral. Esse desenvolvimento integral é uma das marcas do segundo período da Paideia grega, uma formação completa, Portanto, em nosso entendimento, a Paidia claramente é um dos mecanismos sociais que auxilia o desenvolvimento da concepção de Paideia, uma vez que o jogo funciona como uma das primeiras experiências interativas e baseadas em regras, as quais eram valorizadas pela cultura grega.

\section{www.prometeica.com}




\section{Referências}

ARISTÓTELES. A política. 3. ed. São Paulo: Martins Fontes, 2006. 321 p. (Clássicos). Tradução de: Roberto Leal Ferreira.

BARATIERI, Pedro. Dialética, diálogo e retórica: uma leitura do Fedro. 2014. 317 f. Dissertação (Mestrado) - Curso de Programa de Pós-graduação em Filosofia, Universidade Federal de Santa Catarina, Florianópolis, 2014. Disponível em: <https://repositorio.ufsc.br/bitstream/handle/123456789/128646/329751.pdf? sequence $=1>$. Acesso em: 02 out. 2015.

BRAGA, Marco. A Nova Paidéia: Ciência e Educação na Construção da Modernidade. Rio de Janeiro: E-papers, 2000. 144 p. Disponível em: <https://books.google.com.br/books>. Acesso em: 19 ago. 2015.

BROUGÈRE, Gilles. Jogo e educação. 2. ed. Porto Alegre: Artmed, 1998a. 218 p. Tradução: Patrícia Chittoni Ramos. Revisão técnica e apresentação à edição brasileira: Gisele Wajskop.

CAILLOIS, Roger. Os jogos e os homens: a máscara e a vertigem. Lisboa: Cotovia, 1990. 228 p. Tradução de: José Garcez Palha.

CAMBI, Franco. História da pedagogia. São Paulo: UNESP, 1999. 701 p. Tradução: Álvaro Lorencini.

HENRIQUES, Maria Teresa dos Santos. O jogo teatral na construção do diálogo filosófico: uma experiência pedagógica. 2005. 132 f. Dissertação (Mestrado) - Curso de Faculdade de Ciências Humanas e Sociais, Universidade do Algarve, Faro/Portugual, 2005. Disponível em: <http://sapientia.ualg.pt/handle/10400.1/5146>. Acesso em: 03 out. 2015.

HUIZINGA, Johan. Homo ludens: o jogo como elemento da cultura. 4.ed. São Paulo: Perspectiva, 200o, 162 p. (Coleção estudos. Filosofia). Tradução: João Paulo Monteiro. Disponível em: < http://jnsilva.ludicum.org/Huizinga_HomoLudens.pdf >. Acesso em: 10 mar. 2015.

JAEGER, Werner. Paidéia: A formação do homem grego. 3. ed. São Paulo: Martins Fontes, 1995. 1413 p. Tradução: Artur M. Parreira.

KOHAN, Walter Omar. Infância e educação em Platão. Educação e Pesquisa, São Paulo, v. 29, n. 1, p.11-26, jun. 2003. Semestral. Disponível em: <http://www.scielo.br/pdf/ep/v29n1/a02v29n1.pdf>. Acesso em: 03 jul. 2015.

MANACORDA, Mario Alighiero. História da educação: da antiguidade aos nossos dias. 3. ed. São Paulo: Cortez, 1992. (Memória da educação). Tradução de: Gaetano Lo Monaco.

PLATÃO. A república. São Paulo: Difusão Européia do livro, 1965. 1. V. Livro I-IV. Clássicos Garnier. Tradução de J. Guinsburg. Disponível em:

https://saudeglobaldotorg1.files.wordpress.com/2013/o8/te1-platc3a3o-a-republica.pdf

PLATÃO. Diálogos: Leyes. Madri-España: Gredos, 1999. 8 v. (Libros I-VI). Tradução de: Francisco Lisi.

PLATÃO. As Leis. (s/d). Disponível em:

$<$ https://leandromarshall.files.wordpress.com/2012/05/platc3a3o-as-leis.pdf >. Acesso em: O3 out. 2015

PLATÃO. A república. 3. ed. Belém: EDUFPA, 2000. 470 p. Tradução de Carlos Alberto Nunes. Disponível em: <http://copyfight.me/Acervo/livros/PLATA\%CC\%83O.\%20A\%2oRepu\%CC \%81blica\%20(EDUFPA).pdf > . Acesso em: 03 out. 2015

PLATÃO. A república. 9. ed. Lisboa: Fundação Calouste Gulbenkian, 2001. Introdução, tradução e notas de Maria Helena da Rocha Pereira. 